\title{
Multimetal deposition method for detection of latent fingerprints: a review
}

\author{
Gurvinder S. Sodhi ${ }^{{ }^{*}}$ and Jasjeet Kaur ${ }^{2}$
}

\begin{abstract}
Multimetal deposition is a versatile technique of detecting latent fingerprints on porous items, for example, fabric tape, masking tape, cardboard; on semi-porous items, for example, expanded polystyrene, latex gloves, waxed paper; as well as on non-porous items, for example, metals and plastics. It is so named because it is a two-step process, the first involves deposition of gold and the second deposition of silver on the ridges, thereby visualizing the latent impressions. Although a technique with a very wide range of applications, multimetal deposition is not very popular since the process of detecting fingerprints is quite cumbersome. In its modified form, called multimetal deposition II, some of the demerits of the original method are overcome. Multimetal deposition III and IV endeavor to further improve the performance of this technique. Yet another modification of the original multimetal deposition version is the fluorescent multimetal deposition - a technique which produces a better contrast of the ridges vis-à-vis the background.
\end{abstract}

\section{Background}

A latent fingerprint is formed when the sweat pores of the papillary ridges leave a deposition of perspiration on a surface with which the finger has been brought into contact (Thomas, 1978). Human body possesses the following three types of glands - viz. eccrine, apocrine and sebaceous, the secretions of which contribute to a fingerprint deposit (Knowles, 1978).

Eccrine glands are widely distributed throughout the body and are particularly numerous on the palms of hands and the soles of feet. These glands secrete chemicals as a result of general metabolism and catabolism. Besides water content, eccrine sweat contains up to $1 \%$ of the other substances of which inorganic salts constitute about one-half (Kuno, 1956). The other half is constituted by organic products like urea, creatinine, choline, lactic acid, sugars, uric acid, amino acids and proteins (Scruton et al., 1975). The multimetal deposition technique for detection of latent fingerprints is based on the interaction between these organic biomolecules, especially the amino acids and proteins with colloidal gold particles. The technique is so named because it involves the successive deposition of two metals on the

\footnotetext{
* Correspondence: sodhigs1@rediffmail.com

${ }^{1}$ Forensic Science Unit, S.G.T.B. Khalsa College, University of Delhi, Delhi

110007, India

Full list of author information is available at the end of the article
}

macromolecule components of sweat residue and, in consequence, develops fingerprints on an array of crime scene evidence (Saunders, 1989b). The macromolecules, such as lipids, proteins and peptides present in the fingerprint residue are first stained with colloidal gold and then by a silver developer. The latter step amplifies the gold staining and enhances the clarity of ridge pattern.

The typical laboratory procedure for multimetal deposition is carried out in several steps. The quality of developed fingerprints depends on such parameters as the size of colloidal gold particulates and $\mathrm{pH}$ of test solution (Jones, 2002). The dark gray coloured impressions are difficult to visualize if the background surface itself is dark or patterned. To overcome this problem, Becue et al. (Becue et al., 2006) recommended the use of gold colloids, dispersed in cyclodextrins as the staining solution. The modified method produced dark blue impressions and also reduced the number of operational steps. Subsequently, Stauffer et al. (Stauffer et al., 2007) replaced the silver staining step by gold nanoparticles. This not only eliminated one of the reagents, but also made the technique cost-effective.

\section{Mechanism}

It has been known since long that colloidal gold particles adhere to amino acids, proteins and peptides (Frens, 1973). The multimetal deposition technique of fingerprint 
development relies on the affinity of gold particles for these biomolecules, as these are present in fairly large concentration in sweat residue (Saunders, 1989a).

The methodology is a two-phase process. In the first phase, colloidal gold particles adhere to the amino acid, protein and peptide content of fingerprint deposition, while in the second phase, silver particles get adsorbed on gold layer, improving the contrast (Holgate et al., 1983). The process was adopted from a sensitive immunogold-silver staining procedure, whereby the secondary colloidal silver deposition step improved the labelling of proteins (Champod et al., 2004).

The colloidal gold particles are produced by the reduction of hydrogen tetrachloroaurate(III), commonly referred to as tetrachloroauric acid, by citric acid.

$$
\underset{\text { Citric acid }}{2 \mathrm{H}\left[\mathrm{AuCl}_{4}\right]+\underset{3 \mathrm{C}_{6} \mathrm{H}_{8} \mathrm{O}_{7}}{32 \mathrm{Au}}+\underset{\text { 3-Ketoglutaric acid }}{3 \mathrm{C}_{5} \mathrm{H}_{6} \mathrm{O}_{5}}+8 \mathrm{HCl}+3 \mathrm{CO}_{2}}
$$

Besides gold particulates, 3-ketoglutaric acid is one of the products. The structures of citric acid and 3ketoglutaric acid are shown in Figs. 1 and 2, respectively.

The working solution of multimetal deposition method also contains sodium citrate, the structure of which is depicted in Fig. 3.

The citrate anions, furnished by sodium citrate, engulf the colloidal gold particles and impart a negative charge to these, as is shown in Fig. 4.

The amino acids (Fig. 5a; $\mathrm{R}$ is an alkyl or aryl group) or their fragments in proteins and peptides exist as zwitterions under neutral conditions (Fig. 5b). However, under acidic conditions, the amino acids acquire an overall positive charge, as shown in Fig. $5 \mathrm{c}$.

Citric acid brings the $\mathrm{pH}$ of the working solution in 2.5-2.8 range, thereby inducing a positive charge on amino acids present in sweat residue.

Thus the colloidal gold particles bear a negative charge (Fig. 4) and the amino acids bear a positive charge (Fig. 5c). The electrostatic attraction between the two chemical entities is responsible for the adherence

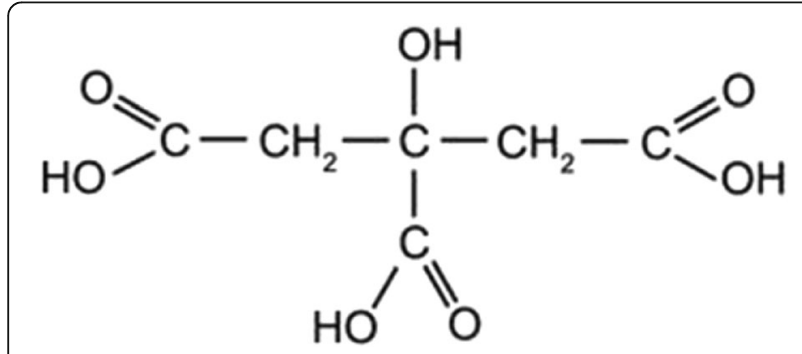

Fig. 1 Structure of citric acid

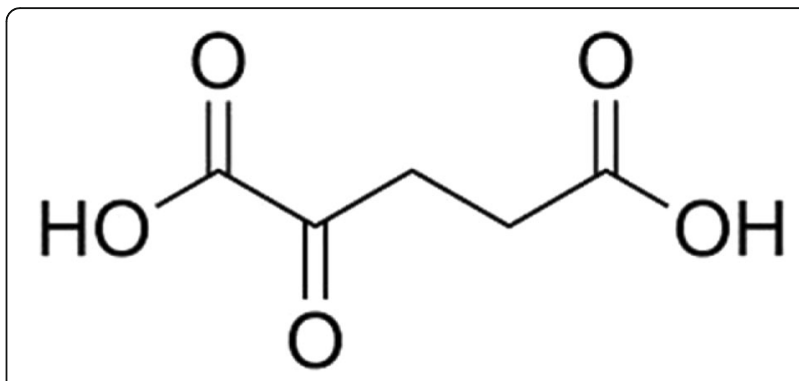

Fig. 2 Structure of 3-ketoglutaric acid

of gold particles on amino acid, protein and peptide content of sweat residue.

It is pertinent to state that citric acid performs two functions: Firstly, it reduces hydrogen tetrachloroaurate(III) ion to colloidal gold, and secondly, brings the $\mathrm{pH}$ of the working solution in the desired range.

The gold particles adsorbed on amino acid, protein and peptide content of fingerprint residue do not impart a pronounced color to the ridges. Nevertheless, these provide a site for the nucleation of silver particles which, in turn, are produced by the reduction of silver(I) ions by iron(II) ions.

$$
\mathrm{Ag}^{+}+\mathrm{Fe}^{2+} \rightleftharpoons A g^{0}+\mathrm{Fe}^{3+}
$$

Being a reversible reaction, there are chances that it may precede from right to left. However, the citrate ions complex with iron(III) ions and remove these from the equilibrium system, pushing the reaction to the right.

The silver particles then settle on the colloidal gold, imparting a dark gray or black color to the ridges. A schematic diagram, showing the adsorption of gold on ridges, followed by adsorption of silver on gold is shown in Fig. 6.

\section{Preparation of reagents}

The following solutions are prepared for developing latent fingerprints by multimetal deposition technique.

\begin{tabular}{ll}
\hline Solution & Ingredient \\
\hline A & $1 \mathrm{~g}$ Hydrogen tetrachloroaurate(III) in $10 \mathrm{~mL}$ distilled water \\
B & $1 \mathrm{~g}$ Sodium citrate in $100 \mathrm{~mL}$ distilled water \\
C & $1 \mathrm{~mL}$ Polyethylene glycol in $100 \mathrm{~mL}$ distilled water \\
D & $4.8 \mathrm{~g}$ Citric acid in $50 \mathrm{~mL}$ distilled water $(0.1 \mathrm{M})$
\end{tabular}

Working solution I or the colloidal gold solution is prepared as follows. Place $1 \mathrm{~mL}$ of solution A in about $950 \mathrm{~mL}$ distilled water. Mix thoroughly and heat to 


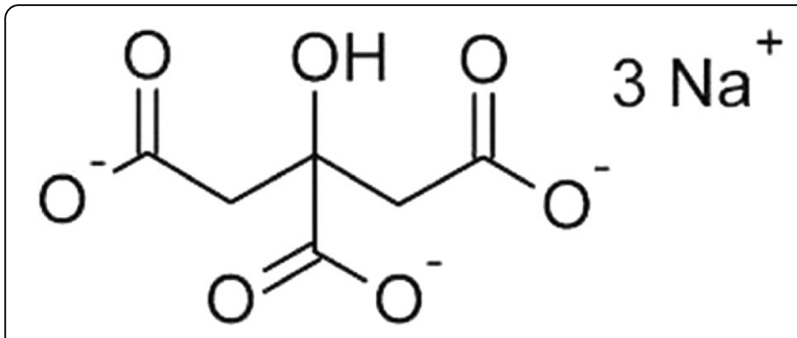

Fig. 3 Structure of sodium citrate

gentle boiling. Add $15 \mathrm{~mL}$ of solution $\mathrm{B}$ and continue to boil till the contents acquire a port-wine color. Turn off the heat source, and while the mixture is still hot, add $5 \mathrm{~mL}$ of a liquid detergent. Agitate to mix the contents thoroughly. Cool and add $10 \mathrm{~mL}$ of solution C. Adjust the $\mathrm{pH}$ to $2.5-2.8$ by adding $1-1.5 \mathrm{~mL}$ of solution $\mathrm{D}$. Make up the volume to $1000 \mathrm{~mL}$. Store the working solution I in an absolutely clean vial in a refrigerator.

The following solutions are prepared next.

\begin{tabular}{ll}
\hline Solution & Ingredient(s) \\
\hline $\mathrm{E}$ & $\begin{array}{l}20 \mathrm{~g} \text { Silver nitrate in } 100 \mathrm{~mL} \text { distilled water (store in a dark } \\
\text { container) }\end{array}$ \\
$\mathrm{F}$ & $\begin{array}{l}16 \mathrm{~g} \text { Ferric nitrate, } 44 \mathrm{~g} \text { ferrous ammonium sulfate, } 11 \mathrm{~g} \text { citric } \\
\text { acid and } 0.25 \mathrm{~mL} \text { liquid detergent in } 1000 \mathrm{~mL} \text { distilled water }\end{array}$ \\
\hline
\end{tabular}

Working solution II or the modified physical developer solution is prepared as follows. Add $10 \mathrm{~mL}$ of solution $\mathrm{E}$ to $990 \mathrm{~mL}$ of solution F. Agitate to mix thoroughly. The shelf life of this solution is just 15-20 min and therefore it should be formulated immediately before being used.

\section{The fingerprint development process}

Latent fingerprints are developed by the following procedure.
- The item bearing latent prints is placed in a tray and covered with distilled water. The tray is rocked gently by using a shaker.

- The item is placed in another tray to which working solution I is added. The tray is shaken for 30-45 min. If more than one item is placed in the tray, these are not allowed to overlap.

- The item is taken out of the working solution I and rinsed several times with distilled water. Faint fingerprints begin to appear.

- The item is then placed in another tray and working solution II is poured over it. The solution is agitated for 5-15 $\mathrm{min}$.

- The item is washed with water several times, till the washings are no longer yellow and turbid.

- The developed fingerprints which are dark gray or black are photographed.

- The item is allowed to dry under natural conditions and thereafter, the prints are lifted with the aid of a fingerprint tape.

\section{Modified multimetal deposition technique}

The modified multimetal deposition technique, referred to as multimetal deposition II, is an attempt to make the operational procedures of the original method easier (Slot \& Geuze, 1985). The gold sol produced by following the modified method is more homogeneous, with the particle size of $14 \mathrm{~nm}$. The smaller particles give superior development as compared to the $30 \mathrm{~nm}$ sized gold particulates (Jones et al., 2003) that were used in the original method.

The novel method not only gives more detailed ridge characteristics, but also visualizes pores and edges with greater clarity. As in the original method, $\mathrm{pH}$ is critical to the quality of developed prints, the optimum range being 2.5-2.8. The reduction of silver ions to metallic silver, in this case, is brought about by the reaction of hydroquinone and silver acetate (Slot \& Geuze, 1985).

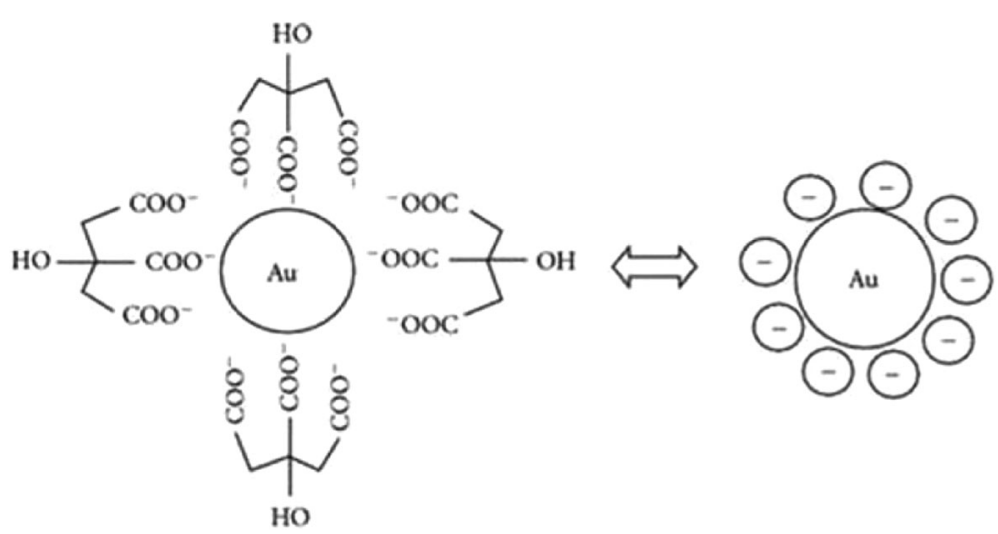

Fig. 4 Colloidal gold particles bearing negative charge 


$$
\begin{array}{ccc}
\mathrm{HOOC}-\mathrm{R}-\mathrm{NH}_{2} & \rightleftharpoons & -\mathrm{OOC}-\mathrm{R}-\mathrm{NH}_{3}^{+} \\
\text {(A) } & & (\mathrm{B}) \\
-\mathrm{OOC}-\mathrm{R}-\mathrm{NH}_{3}^{+}+\mathrm{H}^{+} \rightleftharpoons & \mathrm{HOOC}-\mathrm{R}-\mathrm{NH}_{3}^{+}
\end{array}
$$

(C)

Fig. 5 Amino acids (a) form zwitterions ions (b) which, at low pH, bear positive charge (c)

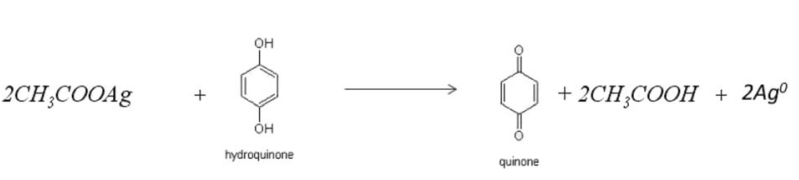

\section{Deactivation of glassware}

When fingerprints are to be developed by multimetal deposition II technique, the glass apparatus has to be rendered scrupulously clean. The process of cleaning glassware, called siliconization is carried out in following steps.

- The entire glassware is soaked overnight in a $10 \%$ solution of 2-ethylhexylsulfate (Fig. 7).

- The apparatus is then rinsed successively with hot and cold water.

- It is then dried in an oven at $100{ }^{\circ} \mathrm{C}$ and allowed to cool at room temperature.

- Thereafter, the apparatus is soaked in a treatment solution for $5 \mathrm{~s}$. The treatment solution is prepared by dissolving $4 \mathrm{ml} 3$-aminopropyltriethoxysilane in $200 \mathrm{~mL}$ acetone. The structure of 3aminopropyltriethoxysilane is depicted in Fig. 8.

- All items of glassware are rinsed twice in distilled water and finally dried in an oven at $42{ }^{\circ} \mathrm{C}$ for $24 \mathrm{~h}$ (Slot \& Geuze, 1985).

\section{Preparation of reagents}

The following solutions are prepared.

\begin{tabular}{ll}
\hline Solution & Ingredient \\
\hline A & $1 \mathrm{~g}$ Hydrogen tetrachloroaurate(III) in $10 \mathrm{~mL}$ distilled water \\
B & $1 \mathrm{~g}$ Sodium citrate in $100 \mathrm{~mL}$ distilled water \\
C & $0.1 \mathrm{~g}$ Tannic acid in $10 \mathrm{~mL}$ distilled water \\
D & $1.05 \mathrm{~g}$ Citric acid in $50 \mathrm{~mL}$ distilled water \\
\hline
\end{tabular}

Working solution I or the colloidal gold solution is prepared as follows. A $0.5 \mathrm{~mL}$ aliquot of solution A is diluted to $400 \mathrm{~mL}$ with distilled water and the contents are heated to $60^{\circ} \mathrm{C}$. In a separate vial, $20 \mathrm{~mL}$ of solution $\mathrm{B}$ and $0.1 \mathrm{~mL}$ of solution $\mathrm{C}$ are diluted to $75 \mathrm{~mL}$ with distilled water and the contents are heated to $60^{\circ} \mathrm{C}$. The contents of the two vials are mixed while hot and the mixture is heated to boiling. It is then allowed to cool at room temperature, transferred to a polythene bottle and stored in a refrigerator.

Immediately before use, the mixture is brought to room temperature and $0.5 \mathrm{~mL}$ of a commercial liquid detergent is added. The $\mathrm{pH}$ of the working solution I is adjusted in the $2.5-2.8$ range by adding $1-2 \mathrm{~mL}$ of solution $\mathrm{D}$.

Working solution II or the buffer/hydroquinone solution is prepared by adding successively $50 \mathrm{~g}$ citric acid, $47 \mathrm{~g}$ sodium citrate and $1 \mathrm{~g}$ hydroquinone to $200 \mathrm{~mL}$ distilled water and stirred till the contents dissolve completely.

Working solution III or the modified physical developer solution is prepared by dissolving $0.2 \mathrm{~g}$ silver acetate in $100 \mathrm{~mL}$ distilled water. Silver acetate stains the background to a lesser extent as compared to silver nitrate solution which is used in the original method. Working solution II is stored in a dark container. This

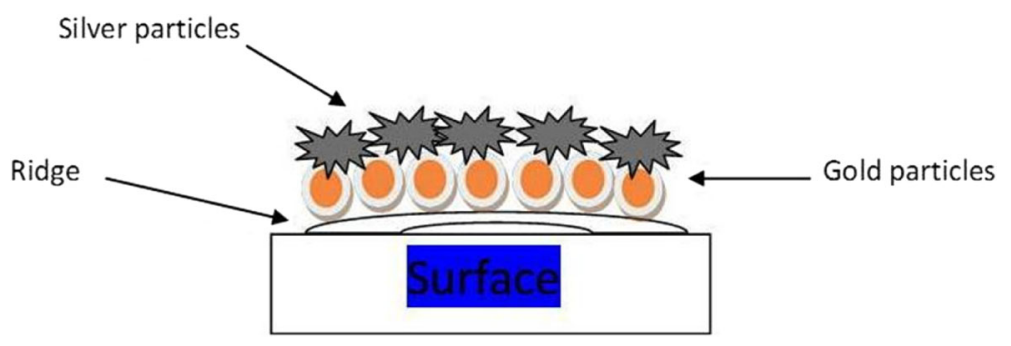

Fig. 6 Mechanism of multimetal deposition technique 


\section{$\mathrm{CH}_{3} \mathrm{CH}_{2} \mathrm{CH}_{2} \mathrm{CH}_{2} \mathrm{CHCH}_{2} \mathrm{OSO}_{2} \mathrm{O}^{-} \mathrm{Na}^{+}$$$
\mathrm{CH}_{2} \mathrm{CH}_{3}
$$

Fig. 7 Structure of 2-ethylhexylsulfate

solution is prepared immediately before processing of fingerprint development.

\section{Process for development of fingerprints}

Latent fingerprints are developed by the following procedure.

- If the item is non-porous in nature, it is given a quick wash with distilled water. Semi-porous and porous items are soaked for about 2 min in distilled water.

- The item is placed in working solution I for $20 \mathrm{~min}$. It is gently agitated.

- The item is then rinsed with distilled water.

- A $100 \mathrm{~mL}$ aliquot of working solution II is diluted to $200 \mathrm{~mL}$ with distilled water. The item bearing latent fingerprints is soaked in this solution for 2-5 min.

- The item is transferred to a tray containing a mixture of $100 \mathrm{~mL}$ working solution III and $100 \mathrm{~mL}$ working solution II. It is soaked for about $20 \mathrm{~min}$ and gently agitated by mounting the tray on a shaker.

- The item is rinsed 2-3 times with fresh batches of distilled water.

- The developed fingerprints are photographed, allowed to dry and finally lifted.

\section{Multimetal deposition III/IV}

The multimetal deposition II technique may be further modified to improve performance. In multimetal deposition III procedure, $30 \mathrm{~nm}$ gold particles are used in concert with the silver acetate/hydroquinone redox reaction. In multimetal deposition $I V, 14 \mathrm{~nm}$ gold particulates are used along with silver(I)/iron(II) redox couple (Jones et al., 2003). Rest of the reagents are same as in conventional multimetal deposition methodology

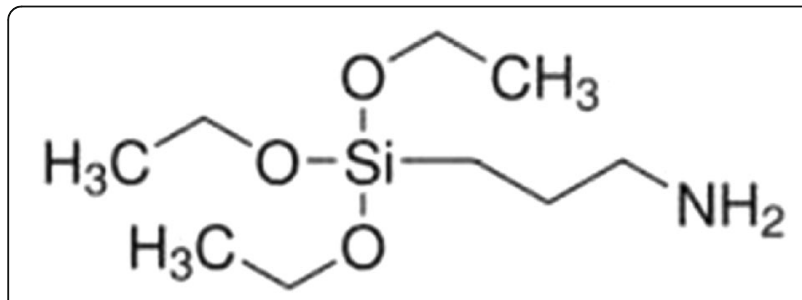

Fig. 8 Structure of 3-aminopropyltriethoxysilane
(Saunders, 1989a). Multimetal deposition IV reveals sharp ridge details but poor contrast as the background surface is darkened. With multimetal deposition III technique, the developed prints are, no doubt, less sharp as compared to multimetal deposition IV, yet the contrast with respect to background is appreciably high.

\section{Fluorescent multimetal deposition}

The fluorescent multimetal deposition technique proves useful to enhance weak, faint fingerprints that are often encountered at crime scenes and also to develop latent impressions on multi-colored surfaces (Becue et al., 2008). As in the original procedure, the first step is the deposition of nanoparticle size gold particles on the fingerprint residue. This is followed by deposition of zinc oxide particles on the gold residue. The zinc oxide, in turn, is produced in situ by the reduction of zinc nitrate with dimethylamine-borane (DMAB).

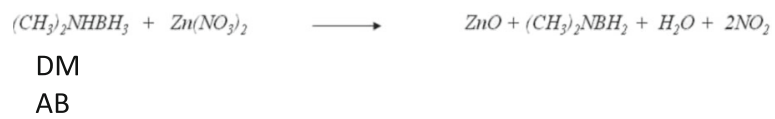

The developed fingerprints show fluorescence when impinged with radiation having $580 \mathrm{~nm}$ radiation.

\section{Assessment of multimetal deposition technique}

Multimetal deposition technique incorporates the principles of both small particle reagent and physical developer (Saunders, 1989b). It detects latent fingerprints on a host of surfaces: Porous, semi-porous and non-porous, moist and dry (Allman et al., 1992). These include paper, glass, floppy disks, adhesive tapes and plastics and polymers. A representative fingerprint developed by multimetal deposition technique on a lamination sheet (Sodhi \& Kaur, 2017) is shown in Fig. 9.

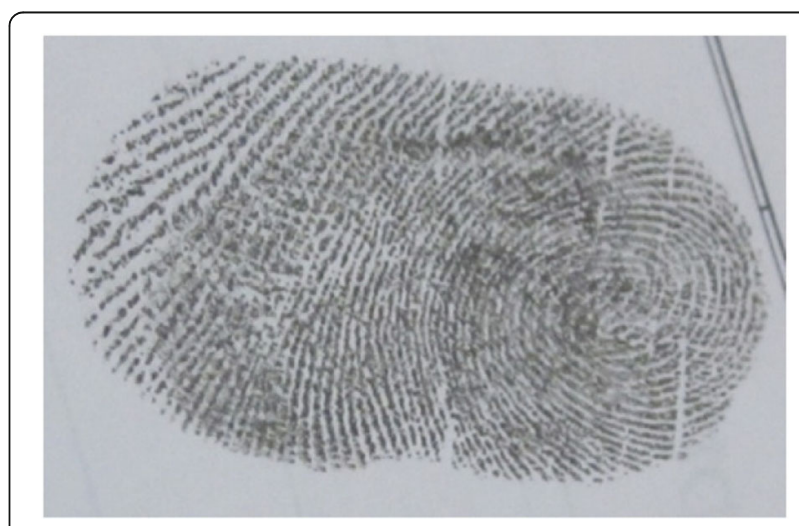

Fig. 9 A fingerprint developed by multimetal deposition technique 
Good results are obtained on articles like paper, tapes, Styrofoam food containers and credit cards, including those having a dark background hue (Saunders, 1989b). Blood prints too may be enhanced by this technique (Ramotowski, 2013). It is also possible to develop good quality fingerprints on cling films, even if the wrappings are moist, crumpled or had been in contact with drugs (Charlton et al., 2015). It is possible to develop impressions which are about 3 months old by this technique (Stauffer et al., 2007). The quality of fingerprints is better than those visualized by vacuum metal deposition, superglue or wet powdering techniques (Fairley et al., 2012).

On semi-porous items, MMD II offers better results as compared to cyanoacrylate fuming and luminescent staining (Jones, 2002). The physical developer technique is more time-consuming and expensive as compared to the modified multimetal deposition methodologies (Sodhi \& Kaur, 2016). Multimetal deposition contributes significantly to the detection of latent fingerprints in the area of forensic science, as well as to staining of proteins in the field of biochemistry.

The versatility of multimetal formulation may be attributed to the ability of the constituent reagents to interact with the sweat residue both on and within the concerned surface (Jones, 2002). The methodology may be used after other techniques of fingerprint detection have been tried. However, it is not successful in cases where ninhydrin has been used in concert with zinc chloride as the developing reagent (Saunders, 1989b). The prints may be transferred from a specific surface to nitrocellulose membrane and then developed.

However, multimetal deposition suffers from some shortcomings too. The procedure is costly and involves several steps (Saunders \& Cantu, 1996). It does not give satisfactory results on cartridge cases and interferes with subsequent analysis of firearms (Donche, 1994; Schetz \& Margot, 2001). Good results are not obtained on patterned surfaces (Stauffer et al., 2007). Most often, the quality of the prints developed by this method on porous items is not up to the mark since a part of the gold sol gets absorbed on the surface, causing high background noise. Leather and cloth items too cannot be processed by multimetal deposition because the organic constituents of these materials interact with colloidal gold, resulting in intensive staining of background.

\section{Conclusion}

The multimetal deposition method of fingerprint detection, as well as its modified versions, involves successive adsorption of gold and silver particulates on the amino acid, protein and peptide content of sweat residue, visualizing the ridges as dark gray or black impression. The technique is not surface-specific, that is, it works on a host of non-porous, semi-porous and porous surfaces.
Despite its broad spectrum applications, the method suffers from several demerits. Too many reagents are required for detection process and the steps involved are complicated. The glassware ought to be meticulously clean. The process entails a high cost. Future research needs to be directed to simplify the operational steps involved in this otherwise useful technique.

\section{Acknowledgements}

Department of Biotechnology, New Delhi.

Funding

Not for this particular work.

\section{Availability of data and materials}

With authors.

\section{Authors' contributions}

Equal, both for survey of literature and compilation. Both authors read and approved the final manuscript.

Ethics approval and consent to participate

Not applicable

\section{Consent for publication}

Not applicable

\section{Competing interests}

The authors declare that they have no competing interests.

\section{Publisher's Note}

Springer Nature remains neutral with regard to jurisdictional claims in published maps and institutional affiliations.

\section{Author details}

${ }^{1}$ Forensic Science Unit, S.G.T.B. Khalsa College, University of Delhi, Delhi 110007, India. ${ }^{2}$ Department of Chemistry, Shaheed Rajguru College of Applied Sciences for Women, (University of Delhi), Vasundhara Enclave, Delhi 110096, India.

Received: 19 April 2017 Accepted: 9 October 2017

Published online: 01 November 2017

\section{References}

Allman DS, Maggs SJ, Pounds CA (1992) The use of colloidal gold/multimetal deposition for the detection of latent fingerprints - a preliminary evaluation. Technical No. 747, Central Research and Support Establishment, Home Office Forensic Science Service, U.K

Becue A, Champod C, Margot P (2006) Use of gold nanoparticles as molecular intermediates for the detection of fingermarks. Forensic Sci Int 168:169-176

Becue A, Scoundrianos A, Champod C, Margot P (2008) Fingermark detection based on the in situ growth of luminescent nanoparticles - towards a new generation of multimetal deposition. Forensic Sci Int 179:39-43

Champod C, Lennard C, Margot P, Stoilovic M (2004) Fingerprints and other ridge skin impressions. CRC Press, Boca Raton, pp 133-134

Charlton DT, Bleay SM, Sears VG (2015) Evaluation of the multimetal deposition process for fingermark enhancement in simulated operational environments. Anal Methods 5:5411-5417

Donche A (1994) Development of latent fingerprints on cartridge casings. Fingerprint Whorld 20(75):13-19

Fairley C, Bleay SM, Sears VG, NicDaeid N (2012) A comparison of multimetal deposition processes utilising gold nanoparticles and an evaluation of their application to 'low yield' surfaces for finger mark development. Forensic Sci Int 217:5-18

Frens $G$ (1973) Controlled nucleation for the regulation of the particle size in monodisperse gold solutions. Nat Phys Sci 241:20-22

Holgate CS, Jackson P, Cowen PN, Bird CC (1983) Immunogold-silver staining: new method of immunostaining with enhanced sensitivity. J Histochem Cytochem 31:938-944 
Jones N (2002) Metal deposition techniques for the detection and enhancement of latent fingerprints on semi-porous surfaces, Ph.D. Thesis. Center for Forensic Science, University of Technology Sydney, Sydney

Jones N, Lennard C, Stoilovic M, Roux C (2003) An evaluation of multimetal deposition II. J Forensic Identification 53:444-488

Knowles AM (1978) Aspects of physicochemical methods for the detection of fingerprints. J Phys E Sci Instrum 11:713-721

Kuno Y (1956) Human Perspiration. Thomas, Springfield

Ramotowski RS (2013) In: Ramotowski RS (ed) Lee and Gaensslen's advances in fingerprint technology, 3rd edn. CRC Press, Boca Raton, pp 66-73

Saunders G (1989a) Multimetal deposition technique for latent fingerprint development. Presented at the 74th Annual Education Conference. International Association for Identification, Florida

Saunders GC (1989b) Multimetal deposition technique for latent fingerprint visualization. Final Progress Report to the U.S. Secret Service, Washington DC

Saunders GC, Cantu AA (1996) Evaluation of several techniques for developing latent fingerprints on unfired and fired cartridge cases. In: Almog J, Springer $E$ (eds) Proceedings of the international symposium on fingerprint detection and identification. Hemed Press, Jerusalem, pp 155-160

Schetz B, Margot P (2001) Technical note: latent fingermarks, colloidal gold and multimetal deposition (MMD). Optimisation of the method. Forensic Sci Int 118:21-28

Scruton B, Robins BW, Blott BM (1975) The deposition of fingerprint films. J Phys D Appl Phys 8:714-723

Slot JW, Geuze HJ (1985) A new method of preparing gold probes for multiplelabelling cytochemistry. Eur J Cell Biol 38:87-93

Sodhi GS, Kaur J (2016) Physical developer technique for detection of latent fingerprints: a review. Egyptian J Forensic Sci 6:44-47

Sodhi GS, Kaur J (2017) Evaluation of multimetal technique for detection of latent fingerprints. Indian Police J (communicated)

Stauffer E, Becue A, Singh KV, Thampi KR, Champod C, Margot P (2007) Singlemetal deposition (SMD) as a latent fingermark enhancement technique: an alternative to multimetal deposition (MMD). Forensic Sci Int 168:e5-e9

Thomas GL (1978) The physics of fingerprints and their detection.

J Phys E Sci Instrum 11:722-731

Submit your manuscript to a SpringerOpen ${ }^{\circ}$ journal and benefit from:

- Convenient online submission

- Rigorous peer review

- Open access: articles freely available online

- High visibility within the field

- Retaining the copyright to your article

Submit your next manuscript at $\boldsymbol{\nabla}$ springeropen.com 